\title{
A Research Programme on Urban Dynamics
}

\author{
Roberto Camagni, Roberta Capello and Andrea Caragliu
}

\begin{abstract}
Over the last three decades, the research group on regional and urban economics at the Politecnico di Milano has carried out studies on theoretical and empirical issues concerning the structure, competitiveness and growth of cities. A broad critical synthesis of this line of research is presented in Camagni et al. (Urban Empire, Edward Elgar, Cheltenham, 2019). In what follows, we focus on two crucial issues that the group has tackled, i.e. optimal city size theory and the empirics of central place theory. Although other issues, like self-organization dynamic models and the concept of city networks, have been elaborated by the group, they are not discussed in this paper.
\end{abstract}

Keywords Optimal city size $\cdot$ Urban hierarchy $\cdot$ Central place theory

\section{Introduction}

Over the last three decades, the research group on regional and urban economics at the Politecnico di Milano has carried out studies on theoretical and empirical issues concerning the structure, competitiveness and growth of cities. A broad critical synthesis of this line of research is presented in Camagni et al. (2019). In what follows, we focus on two crucial issues that the group has tackled, i.e. optimal city size theory and the empirics of central place theory. Although other issues, like self-organization dynamic models and the concept of city networks, have been elaborated by the group, they are not discussed in this paper.

The logical fil rouge connecting different contributions-sometimes explicit, sometimes only implicit and even hidden-became evident by developing this paper, which also allowed us to verify the logical consistency of the overall research programme progressed by the groups on these issues.

R. Camagni $(\varangle) \cdot$ R. Capello · A. Caragliu

Architecture, Built Environment and Construction Engineering-ABC Department, Politecnico di Milano, Milan, Italy

e-mail: roberto.camagni@polimi.it 
The main inspiration for most of the work of our research group originates from a paper presented in 1984 at the Second World Congress of the RSAI (Camagni et al. 1986). This period was characterized by booming scientific creativity with groundbreaking works in fields such as the economics of urban size (Alonso 1971), city systems and urban hierarchy (Beckmann 1958), spatial interaction models (Wilson 1970) and the associated dynamic versions (Harris and Wilson 1978), complex systems, mathematical ecology and self-organization modelling (Prigogine and Stengers 1984; Allen and Sanglier 1981). Camagni et al. (1986) is a theoretical and methodological work, although it has also been supported by empirical verification through a computer simulation. In this work, all these traditionally separated research fields were somewhat merged. Also, the paper added a crucial dimension, i.e. Schumpeterian innovation declined in spatial terms. The result was an eclectic, supply-side self-organization model simulating the dynamics of an urban system (SOUDY).

The logical structure of the model paved the way for a few theoretical hypotheses which, on the one hand, improved existing models and theories on urban structure and growth, and, on the other hand, suggested new directions for further theoretical advances and empirical validations. In what follows, we will deal with two major fields of analysis in detail, using the SOUDY model as a guiding light.

\section{On Optimal City Size}

In the early 1970s, urban economics frequently dealt with the identification of an optimal city size, whereby the distance between benefits and costs is maximized. In particular, urban size optimality may be defined in terms of (i) minimum city size (corresponding to the size at which average benefits begin to outvalue costs); (ii) cost minimization (where, with benefits remaining constant, costs are minimized); (iii) per capita optimal city size (i.e. city size associated to the maximum vertical distance between average benefits and costs, usually interpreted as the optimal size for dwellers); (iv) benefits maximization; (v) socially desirable optimal city size, corresponding to the golden rule where marginal costs equal marginal benefits. This condition is usually interpreted as the view of the rational national planner; and (vi) maximum city size, corresponding to the largest city size whereby average costs equal average benefits (Alonso 1971).

Yet, since the late 1970 s research on optimal city size received relatively little attention. Richardson first criticized the optimal city size theory, arguing that since cities do not perform the same functions, they differ in terms of both costs and benefits. This difference logically makes it impossible for cities to share the same optimal size. Later on, Henderson (1985) questioned the validity of the optimal city size theory, claiming that each city is characterized by a specific production function. In fact, the same critique was also discussed by Alonso (1971), acknowledging that an optimal size should be sought for each city. The logical consequence would be a unique optimal city size for each individual city. 
Later research overcame some of the limitations mentioned above by focusing on the fifth class of city size optimality, where marginal location costs equal marginal location benefits. Within a system in spatial balance, a rational planner looks at urban optimal sizes through marginal conditions (Camagni et al. 2013). The model discussed in this last paper delivers a continuum of equilibrium city sizes, due to rational consumers deciding their locations on the basis of a classical " $M C=M B$ "1 optimal condition. This framework also allows for a comparison on a cross-section of cities solving the logical impossibility stemming from the Henderson critique. The model is also supported by an empirical assessment of the factors at the core of benefits and costs, determining equilibrium city size irrespective of their dimensions. These determinants encompass the quality of functions hosted but also other economic, social and environmental factors. The model strikes a balance between the dichotomy of "one vs. infinite optimal sizes": "cities are supposed to share the same cost and production functions with heterogeneous, substitutable factors" (economic functions and other context conditions). Also, "each of them maintains its specificity and, consequently, its 'equilibrium' size, but comparability and possibility of running cross-sectional analyses is saved, and also possibility of devising policy strategies for urban growth and containment" (Camagni et al., p. 313).

However, the remnants of these empirical estimates remain unexplained, or, to put it more accurately, amenable to alternative explanations. Along with true i.i.d. disturbances, residuals also capture potentially omitted variables such as good or bad governance, which may potentially sustain population levels above or below structural equilibrium ones.

\section{On Urban Hierarchy and Central Place Theory}

Central place theory (henceforth, CPT) explains the existence of urban systems as the result of the tension underlying centripetal and centrifugal forces, which create regular structures whereby cities of different ranks coexist and, in the Lösch version, can focus on performing different economic activities.

This theory introduced several fundamental advances in our understanding of urban systems. One such improvement lies in the role played by functions (in Christallerian contributions, specific per rank) in explaining the spatial distribution of cities across a system. The rank of a city explains its function, and therefore its size, leaving within an urban system space for cities of varying sizes. Paradoxically, this result was indirectly neglected for several years by the modern spatial equilibrium approach à la Von Thünen-Alonso-Fujita (Camagni 1992). Theoretical neoclassical models of stylized cities typically work on the assumption of location choice indifference, which posits that lower accessibility to the centre is compensated by lower rents and higher environmental quality. Extending the same approach to city systems equilibria, indifference in location choices is satisfied only when cities provide the

\footnotetext{
${ }^{1} \mathrm{MC}$ : Marginal Costs; MB: Marginal Benefits.
} 
same advantages and disadvantages to firms and dwellers. This condition remains valid only when cities share the same size (Camagni 1992, Sect. 6.6).

However, CPT is not free from shortcomings. One such limitation is related to their inherently static approach: proof being that in these models relative city rankings remain stable over time. While this result is acceptable over the short/medium run, it clearly cannot explain long-run urban growth processes. While some have tried to overcome this limitation at least in terms of comparative statics (Parr 1981), there is still a chance to explain the diverging development patterns of cities over the long run.

In this sense, following the newly developed self-organization approach to the dynamics of complex systems (Prigogine and Stengers 1984) and in particular its application to the evolution of urban systems (Allen and Sanglier 1981; Dendrinos and Mullally 1981; Bertuglia et al. 1987), the SOUDY model (Camagni et al. 1986) introduced a dynamic and evolutionary approach, in theoretical, mathematical and simulation terms. The dynamics of each city in the model, interacting within urban systems, happens through two distinct processes:

(i) a process of constrained dynamics, causing demographic growth (within efficient size intervals) towards an attractor (net urban benefits) and linked to the hierarchical level of each function;

(ii) a process of structural dynamics, engendered by an innovation leap achieved by each city. This happens through the acquisition of new functions, relating to a higher hierarchical level, allowing higher profits, balancing the superior costs of larger dimensions. In the SOUDY model, the probability of transition depends on an endogenous dynamic instability condition, where each city overcomes the size threshold for the appearance of the superior function. This can potentially lead to the acquisition of the new function (or to the loss of previous functions) and consequently to relevant bifurcations in the development path.

Following up to the conceptual novelties of the SOUDY model, the development path of cities determined by normal, multiplier-type dynamics and by structural dynamics led by internal innovation was empirically investigated identifying three hierarchical ranks (small, medium and large cities) in the European urban system (Camagni et al. 2015a, b). Interpreting urban growth as net returns to urban scale, the assumption of an inverted U-shaped relationship between city size and agglomeration economies inside each rank was found to be statistically significantly verified, along with the evidence of the possibility, for dynamic cities, to escape decreasing returns through innovation.

Moreover, Camagni et al. (2015a, b) find that:

(i) the intensity of the following factors determines increasing returns irrespective of city size: the quality of the activities hosted, the quality of production factors, the density of external linkages and cooperation networks, the quality of urban infrastructure-internal and external mobility, education, public services;

(ii) large, as well as medium and small cities, may experience a halt in their growth path, even a decline, when they grow without a simultaneous increase in the 
endowment of these factors. This is what has been termed long-term structural dynamics (Camagni et al. 2015a).

This implies that some large cities escape agglomeration diseconomies, despite their large dimensions; by the same token, some small ones may face diseconomies if unable to implement innovative strategies and functional upgrading or to broaden their networks with other cities across short but also long distances through cooperative agreements relating to infrastructure, top public services or $\mathrm{R} \& \mathrm{D}$ facilities.

Within CPT, there is still considerable room for further advances. Particularly, there seems to be a general lack of consensus regarding the very definition of urban ranks. What do "large" and "medium" mean when defining urban ranks? While, from a general equilibrium perspective, city sizes are distributed along a continuum of functions and roles, structural breaks still seem to characterize urban systems, thus strengthening the case for the existence of different production functions, and different stocks of production factors for cities of different ranks. Ideally, theoretical models should follow suit and accommodate rank thresholds.

An important step forward in this sense is the critique of a number of theoretical shortcuts in neoclassical urban economics (Camagni et al. 2016) which assume that agglomeration economies (i.e. city size) automatically lead to urban growth (Krugman 1991; Glaeser et al. 2001; Glaeser 2011). Henderson (2010) argues that the "association between urbanization and development (...) is an equilibrium not causal relation" (p. 518) and that "urbanization per se does not cause development" (p. 515). The point made by the authors is that "along an average productivity curve rising with urban size, reading the size-derivative as a time-derivative will be mistaken and, beyond that, implies a circular reasoning: 'if a city grows demographically it will grow economically" (Camagni et al. 2016, p. 134). A second critique also posed by the authors suggests the use of net rather than gross measures of urban efficiency when measuring agglomeration economies. This implies reaching beyond per capita GDP, productivity and wages in order to also include urban costs (as argued in Richardson 1978). Thirdly, in their empirical estimates (based on European metro areas), Camagni et al. (2016) find that:

(i) In static terms, net overall urban benefits (urban land rent) display a U-shaped relationship with urban size, suggesting the presence of net increasing returns to urban scale;

(ii) On the other hand, from a dynamic perspective, this relationship fails when it comes to interpreting urban growth. In fact, urban dynamics as measured by net benefit growth rates show no relation to initial urban size or density. Instead, results suggest that growth is positively associated with the upgrading of urban functions, the development of the nearby urban system and, once again, the capability of establishing long-distance cooperative agreements with other cities. These results call for a dynamic approach to explaining agglomeration economies (Camagni et al. 2016).

Despite consistent efforts, urban economics still has a long way to go. As frequently advocated (see e.g. Duranton and Puga 2004), the relative strength of agglomerative forces is still not fully understood. More specifically, there seems to be room 
to seek for more broadly defined dependent variables in agglomeration economy regressions (this is the case of the recent wave of studies on urban wellbeing and quality of life; see Lenzi and Perucca 2016, for a recent review) and independent variables (i.e. how to measure sources of urban efficiency).

\section{Conclusions}

The main goal of the present work is to present a selection of highlights from the scientific study of urban economics as carried out by the research group in regional science active at the Politecnico di Milano over the last thirty years, with a particular focus on optimal city size theory and on the empirics of central place theory. The specificity of this long-term research programme lies in taking the challenge launched by Alan Wilson in the early 1980s, i.e. the need to develop a unitary approach to urban economics, bringing together theoretical areas which were developed in total isolation. These have been labelled the five principles of urban economics (agglomeration, accessibility, interaction, hierarchy and development; Camagni 1992, Introduction).

The starting point of this journey was the construction of a theoretical and simulation model of urban system dynamics, driven by the capability to innovate in the functions hosted by each city (SOUDY model; Camagni et al. 1986). Schumpeterian innovation, generated both by private entrepreneurship and public leadership, and the consequent structural dynamics, were suggested as the main driving forces of urban growth. Subsequently, other issues were explicitly inserted into the picture: agglomeration economies, urban and environmental quality, city networks and high-level urban functions.

Attention was also paid to pinpointing the logical shortcuts of an automatic relationship between agglomeration economies and growth. Again, structural change is identified as the factor allowing faster growth of urban benefits to overcome the increase of urban costs, rather than sheer size. Remarkable empirical results have been achieved to prove these assumptions.

\section{References}

Allen, P. M., \& Sanglier, M. (1981). Urban evolution, self-organization and decision-making. Environment and Planning A, 13, 167-183.

Alonso, W. (1971). The economics of urban size. Papers and Proceedings of the Regional Science Association, 26, 67-83.

Beckmann, M. J. (1958). City hierarchies and the distribution of city size. Economic Development and Cultural Change, 3, 243-248.

Bertuglia, S., Leonardi, G., Ocelli, S., Rabino, G., Tadei, R., \& Wilson, A. (Eds.). (1987). Urban Systems: Contemporary approaches to modelling. London (UK): Croom Helm.

Camagni, R. (1992). Economia Urbana: principi e modelli teorici. Firenze: La Nuova Italia. French translation (1996): Principes et modèles de l'économie urbaine, Paris: Economica. 
Camagni, R., Capello, R., \& Caragliu, A. (2013). One or infinite optimal city sizes? In search for an equilibrium size for cities. Annals of Regional Science, 51(2), 309-341.

Camagni, R., Capello, R., \& Caragliu, A. (2015a). The rise of second-rank cities: What role for agglomeration economies? European Planning Studies, 23(6), 1069-1089.

Camagni, R., Capello, R., \& Caragliu, A. (2015b). Agglomeration Economies in large vs. small cities: Similar laws, high specificities. In K. Kourtit, P. Nijkamp, \& R. Stough (Eds.), The rise of the city (pp. 85-116). Cheltenham: Edward Elgar.

Camagni, R., Capello, R., \& Caragliu, A. (2016). Static vs. dynamic agglomeration economies: Spatial context and structural evolution behind urban growth. Papers in Regional Science, 94(1), 133-159.

Camagni, R., Capello, R., \& Caragliu, A. (2019). A scientific program on urban performance and dynamics. In E. Glaeser, K. Kourtit, \& P. Nijkamp (Eds.), Urban empire. Cheltenham: Edward Elgar.

Camagni, R., Diappi, L., \& Leonardi, G. (1986). Urban growth and decline in a hierarchical system: A supply-oriented dynamic approach. Regional Science and Urban Economics, 16(1), 145-160.

Dendrinos, D., \& Mullally, H. (1981). Evolutionary patterns of urban populations. Geographical Analysis, 4, 328-344.

Duranton, G., \& Puga, D. (2004). Micro-foundations of urban agglomeration economies. In V. Henderson \& J. F. Thisse (Eds), Handbook of regional and urban economics (Vol. 4, pp. 20632117).

Glaeser, E. L. (2011). Triumph of the city: How our greatest invention makes us richer, smarter, greener, healthier, and happier. New York: Penguin Books.

Glaeser, E. L., Kolko, J., \& Saiz, A. (2001). Consumer city. Journal of Economic Geography, 1(1), $27-50$.

Harris, B., \& Wilson, A. (1978). Equilibrium values and dynamics of attractiveness terms in production-constrained spatial interaction models. Environment and Planning A, 10, 371-388.

Henderson, J. V. (1985). Economic theory and the cities (2nd ed.). Orlando (FL): Academic Press. Henderson, J. V. (2010). Cities and development. Journal of Regional Science, 50(1), 515-540.

Krugman, P. (1991). Increasing returns and economic geography. Journal of Political Economy, 99(3), 483-499.

Lenzi, C., \& Perucca, G. (2016). Are urbanized areas source of life satisfaction? Evidence from EU regions. Papers in Regional Science, online first.. https://doi.org/10.1111/pirs.12232.

Parr, J. B. (1981). Temporal change in a central-place system. Environment and Planning A, 13(1), 97-118.

Prigogine, I., \& Stengers, I. (1984). Order out of chaos. New York (NY): Bantam Books.

Richardson, H. W. (1978). Regional and urban economics. London (UK): Penguin.

Wilson, A. G. (1970). Entropy in urban and regional modelling. London: Pion.

Open Access This chapter is licensed under the terms of the Creative Commons Attribution 4.0 International License (http://creativecommons.org/licenses/by/4.0/), which permits use, sharing, adaptation, distribution and reproduction in any medium or format, as long as you give appropriate credit to the original author(s) and the source, provide a link to the Creative Commons license and indicate if changes were made.

The images or other third party material in this chapter are included in the chapter's Creative Commons license, unless indicated otherwise in a credit line to the material. If material is not included in the chapter's Creative Commons license and your intended use is not permitted by statutory regulation or exceeds the permitted use, you will need to obtain permission directly from the copyright holder. 